\title{
A COMPARATIVE STUDY OF SKIM-MILK AND EGG YOLK TO FREEZING OF THE BULL SEMEN
}

\author{
SANTOS, I.W. ${ }^{1}$; WEISS, R.R ${ }^{2}$; SOUZA, J.C. ${ }^{3}$ \\ ${ }^{1}$ Departamento de Medicina Veterinária - UFPR - Palotina, PR; \\ ${ }^{2}$ Departamento de Medicina Veterinária - UFPR - Curitiba,PR ; \\ ${ }^{3}$ Departamento de Zootecnia - UFPR - Palotina, PR.
}

The aim of this study was to compare skimmed milk with yolk egg for cryopreservation of bovine semen. Four bulls, being three Bos taurus and one Bos indicus were used in this study. The ejaculated was divided in two parts. The first one was diluted inTRISglycerol-skim-milk (TGM) and the second one in TRIS-glycerol-yolk(TGY), both for the "One Step" methodology and bottling in aliquots of $0,5 \mathrm{~mL}$. After the semen was kept 60 minutes at $5^{\circ} \mathrm{C}$ and then at $-120^{\circ} \mathrm{C}$ for 20 minutes on nitrogen and then quickly deeped in liquid nitrogen and kept in the cryobiologic bottle. The thawing was performed in a water bath at $37^{\circ} \mathrm{C}$ for 25 minutes followed by immediate analysis of the motility and vigor. A semen sample was taken for acrossomic retention examination by the Cerovsky methodology. The straw was shut again and incubate at $46^{\circ} \mathrm{C}$ for 30 minutes for the step of TTR, the motility and vigor analyzed again. Significance was not observed between TGM and TGY to acrossomic retention and to vigor after TTR. However, the motility and vigor after thawing were superior for $\operatorname{TGY}(P<0,05)$. The use of skim-milk for bovine semen cryopreservation is possible.

Key Words: Skim-milk, cryopreservation, semen, bull. 